Check for updates

Cite this: RSC Adv., 2019, 9, 27743

\title{
Low-temperature selective catalytic dehydrogenation of methylcyclohexane by surface protonics $\uparrow$
}

\author{
Kent Takise, ${ }^{a}$ Ayaka Sato, ${ }^{a}$ Shuhei Ogo, (D) a Jeong Gil Seo, (D) ab Ken-ichi Imagawa, ${ }^{c}$ \\ Shigeru Kado ${ }^{C}$ and Yasushi Sekine (D) *a
}

\begin{abstract}
The methylcyclohexane $(\mathrm{MCH})$-toluene cycle is a promising liquid organic hydride system as a hydrogen carrier. Generally, $\mathrm{MCH}$ dehydrogenation has been conducted over Pt-supported catalysts, for which it requires temperatures higher than $623 \mathrm{~K}$ because of its endothermic nature. For this study, an electric field was applied to $\mathrm{Pt} / \mathrm{TiO}_{2}$ catalyst to promote $\mathrm{MCH}$ dehydrogenation at low temperatures. Selective dehydrogenation was achieved with the electric field application exceeding thermodynamic equilibrium, even at $423 \mathrm{~K}$. With the electric field, "inverse" kinetic isotope effect (KIE) was observed by accelerated proton collision with $\mathrm{MCH}$ on the $\mathrm{Pt} / \mathrm{TiO}_{2}$ catalyst. Moreover, $\mathrm{Pt} / \mathrm{TiO}_{2}$ catalyst showed no methane byproduction and less coke formation during $\mathrm{MCH}$ dehydrogenation. DRIFTS and XPS measurements revealed that electron donation from $\mathrm{TiO}_{2}$ to $\mathrm{Pt}$ weakened the interaction between catalyst surface and $\pi$-coordination of toluene. Results show that the electric field facilitated $\mathrm{MCH}$ dehydrogenation without methane and coke by-production over $\mathrm{Pt} / \mathrm{TiO}_{2}$ catalyst.
\end{abstract}

Received 4th August 2019

Accepted 26th August 2019

DOI: $10.1039 / c 9 r a 06042 a$

rsc.li/rsc-advances and naphthene compounds (i.e. cycloalkanes). ${ }^{6,7}$ At hydrogen generation sites, aromatics are converted to naphthene compounds by catalytic hydrogenation. The reverse reaction: dehydrogenation of naphthene to aromatics, is conducted at hydrogen consumption sites. Among various liquid organic hydrides, the most well-known and promising system is a methylcyclohexane (MCH)-toluene cycle (hydrogen capacity: $6.1 \mathrm{wt} \%$ ) by virtue of its nontoxicity and wider range of liquid phase at $178-374 \mathrm{~K}^{6,7}$

Dehydrogenation of $\mathrm{MCH}$ is an endothermic reaction (as shown in eqn (1)): an energy-consuming process. This reaction has been performed over a Pt-supported catalyst. ${ }^{8}$ Results show high activity for dehydrogenation above $623 \mathrm{~K}$ of reaction temperatures. ${ }^{6,9-11}$ However, Pt-based catalysts are easily deactivated with coke formation and/or toluene fouling during the reaction. ${ }^{12-15}$ Recently, Ir/USY, ${ }^{16}$ partially reduced $\mathrm{Mo} / \mathrm{SiO}_{2},{ }^{17} \mathrm{Pt}-$ $\mathrm{Mo} / \mathrm{SiO}_{2}$ (ref. 11 and 18) catalysts have been reported as effective catalysts for dehydrogenation of $\mathrm{MCH}$.

$$
\begin{gathered}
\mathrm{C}_{7} \mathrm{H}_{14} \rightarrow \mathrm{C}_{7} \mathrm{H}_{8}+3 \mathrm{H}_{2}, \Delta H_{298}^{0}=205 \mathrm{~kJ} \mathrm{~mol}^{-1} \\
\mathrm{C}_{7} \mathrm{H}_{8}+\mathrm{H}_{2} \rightarrow \mathrm{C}_{6} \mathrm{H}_{6}+\mathrm{CH}_{4}, \Delta H_{298}^{0}=-42 \mathrm{~kJ} \mathrm{~mol}^{-1}
\end{gathered}
$$

Feasibility of the organic hydride system depends on the product selectivity and lifetime of $\mathrm{MCH}$ dehydrogenation catalysts. A side-reaction of $\mathrm{MCH}$ dehydrogenation, hydrodemethylation of toluene (as shown in eqn (2)), and coking on the catalyst are key difficulties to be overcome. ${ }^{19-22}$ They lead to production of benzene and methane as by-products, thereby
169-8555 Japan. E-mail: ysekine@waseda.jp

${ }^{b}$ Myongji University, Department of Energy Science and Technology, 116 Myongii-ro, Yongin-si, Gyeonggi-do 17058, Republic of Korea

${ }^{c} R \& D$ Center, Chiyoda Corporation, 3-13, Moriya-cho, Yokohama, Kanagawa, 221oo22, Japan

$\dagger$ Electronic supplementary information (ESI) available. See DOI: 10.1039/c9ra06042a 
increasing the costs of hydrogen purification. ${ }^{19}$ Furthermore, benzene is toxic for humans. ${ }^{23}$ For this study, an electric field was applied over $\mathrm{Pt} / \mathrm{TiO}_{2}$ catalyst to promote $\mathrm{MCH}$ dehydrogenation at lower temperatures without methane or coke byproduction. This report is the first of low-temperature and selective catalytic dehydrogenation of $\mathrm{MCH}$ over $\mathrm{Pt} / \mathrm{TiO}_{2}$ catalyst in an electric field.

\section{Experimental}

\section{Catalyst preparation}

For catalyst preparation, platinum was supported on $\mathrm{TiO}_{2}$ (JRCTIO-16) and $\mathrm{CeO}_{2}$ (JRC-CEO-1) using a wet-impregnation method. After catalyst supports were drenched in $25 \mathrm{~mL}$ of water for $120 \mathrm{~min}$, Pt precursor, i.e. $\mathrm{Pt}\left(\mathrm{NH}_{3}\right)_{4}\left(\mathrm{NO}_{3}\right)_{2}$ (SigmaAldrich Corp.) was added with $15 \mathrm{~mL}$ of diluted water and was dissolved for $120 \mathrm{~min}$ in an evaporator. An adequate amount of platinum precursor was introduced to make $3 \mathrm{wt} \% \mathrm{Pt} / \mathrm{TiO}_{2}$ and $3 \mathrm{wt} \% \mathrm{Pt} / \mathrm{CeO}_{2}$. The obtained solution was dried and calcined at $773 \mathrm{~K}$ for $120 \mathrm{~min}$. The resultant catalyst powder was pressed and sieved to $355-500 \mu \mathrm{m}$. Prepared catalyst was used for the reaction in the electric field without any pre-treatment.

\section{Catalytic activity tests}

A fixed-bed flow type reactor was packed with $200 \mathrm{mg}$ of Ptsupported catalysts to conduct $\mathrm{MCH}$ dehydrogenation. An electric field was applied using two stainless steel electrodes set on upper side and bottom side of the catalyst bed. Catalytic dehydrogenation in the electric field was performed by application of $3.0 \mathrm{~mA}$ of constant current between two electrodes. The reaction temperature was set between 423 to $773 \mathrm{~K}$ with and without the electric field. A thermocouple was placed on the catalyst bed for monitoring the real temperature of the catalyst because Joule heat is expected to increase the catalyst temperature during dehydrogenation in the electric field. $T_{\mathrm{tc}}$ stands for the real catalyst temperature measured by the thermocouple. The reaction gas consisted of $\mathrm{C}_{7} \mathrm{H}_{14}: \mathrm{Ar}=6.4: 30$ (total gas flow rate: $36.4 \mathrm{~mL} \mathrm{~min}^{-1}$ ) at ambient pressure of $0.1 \mathrm{MPa}$. Reactions were conducted in a kinetic region, i.e. diffusion is not a ratedetermining factor. The gaseous products of the reaction were analyzed using GC-TCD (GC-8A; Shimadzu Corp.) and GC-FID (GC-8A; Shimadzu Corp.). The hydrogen yield was defined using the $\mathrm{MCH}$ feed rate $\left(\mu \mathrm{mol} \mathrm{min}^{-1}\right)$ and $\mathrm{H}_{2}$ formation rate $\left(\mu \mathrm{mol} \min ^{-1}\right)$.

$$
\text { Hydrogen yield }(\%)=r_{\mathrm{H}_{2}} /\left(\mathrm{C}_{7} \mathrm{H}_{14} \text { feed rate } \times 3\right) \times 100
$$

The apparent activation energy was estimated over $\mathrm{Pt} / \mathrm{TiO}_{2}$ from Arrhenius plots during $\mathrm{MCH}$ dehydrogenation with and without the electric field. Reaction rates were estimated in kinetic control. The reaction rates were calculated from the $\mathrm{H}_{2}$ formation rate in the same manner as that used for activity tests.

Deposited coke amounts were evaluated using temperature programmed oxidation (TPO) measurements estimating CO or $\mathrm{CO}_{2}$ formation caused by the oxidation of coke. The temperature was increased from $298 \mathrm{~K}$ to $1173 \mathrm{~K}$ at $10 \mathrm{~K} \mathrm{~min}^{-1}$ in the gas composition of $\mathrm{O}_{2}: \mathrm{He}=10: 90\left(\mathrm{~mL} \mathrm{m^{-1 }}\right)$. The product components and coke formation amount indicated a credible mass balance (almost 100\%).

\section{Partial pressure dependency and isotope effects}

Partial pressure dependencies of $\mathrm{MCH}$, toluene, and hydrogen on reaction rates were evaluated over $\mathrm{Pt} / \mathrm{TiO}_{2}$ catalyst to elucidate the role of the electric field. Results were obtained with and without the electric field at the same $\mathrm{MCH}$-conversion-level i.e. (a) at $423 \mathrm{~K}$ with the electric field and (b) at $498 \mathrm{~K}$ without the electric field. For this experiment, the total feed gas flow was set as $56.4 \mathrm{~mL} \mathrm{~min}^{-1}$ at ambient pressure of $0.1 \mathrm{MPa}$. Then, the gas ratio was modified as $\mathrm{C}_{7} \mathrm{H}_{14}: \mathrm{Ar}=(3.2,6.4,9.6,11.3):(53.2$, 50.0, 46.8, 45.1), $\mathrm{C}_{7} \mathrm{H}_{14}: \mathrm{C}_{7} \mathrm{H}_{8}: \mathrm{Ar}=6.4:(1.0,2.0,3.0$, $4.0):(49.0,48.0,47.0,46.0)$ and $\mathrm{C}_{7} \mathrm{H}_{14}: \mathrm{H}_{2}: \mathrm{Ar}=6.4:(4.0,7.0$, $9.0,12.0):(46.0,43.0,41.0,38.0)$. Reaction rates were determined by the $\mathrm{H}_{2}$ formation rate measured using GC-TCD (GC8A; Shimadzu Corp.).

$\mathrm{MCH}$ dehydrogenation was conducted by supplying isotopes of $\mathrm{MCH}$ and $\mathrm{H}_{2}$ to investigate isotope effects with and without the electric field. Accordingly, the reaction gas consisted of $\mathrm{C}_{7} \mathrm{H}_{14}$ (or $\mathrm{C}_{7} \mathrm{D}_{14}$; denoted as $\left.\mathrm{MCH}_{\mathrm{D}}\right): \mathrm{H}_{2}\left(\right.$ or $\left.\mathrm{D}_{2}\right): \mathrm{Ar}=6.4: 4.0: 46.0$. The total gas flow rate was $56.4 \mathrm{~mL} \mathrm{~min}^{-1}$. Reaction rates were assessed by the formation rates of $\mathrm{H}_{2}, \mathrm{HD}$, and $\mathrm{D}_{2}$.

\section{DRIFTS measurements during toluene feed over $\mathrm{Pt} / \mathrm{TiO}_{2}$ and $\mathrm{Pt} / \mathrm{CeO}_{2}$}

DRIFTS (diffuse reflectance for infrared Fourier transform spectroscopy) measurements were conducted to investigate toluene adsorption over $\mathrm{Pt} / \mathrm{TiO}_{2}$ and $\mathrm{Pt} / \mathrm{CeO}_{2}$ catalysts using a Fourier transform infrared spectrometer (FT/IR-6100; Jasco Corp.). Teflon-made DRIFTS cells were packed with sieved catalyst, on which two stainless steel electrodes were set to apply the electric field. Detailed information related to the apparatus of DRIFTS measurement is presented elsewhere. ${ }^{24}$ Although the electric field was stabilized over $\mathrm{Pt} / \mathrm{TiO}_{2}$ in a fixed-bed flow-type reactor, electrical discharge has occurred all the time over packed $\mathrm{Pt} / \mathrm{TiO}_{2}$ in the DRIFTS cell. Therefore, the experiment with the electric field was performed only over $\mathrm{Pt} / \mathrm{CeO}_{2}$ for safety reasons. Toluene gas was introduced into the measurement chamber for $30 \mathrm{~min}$. Subsequently, in the case of $\mathrm{Pt} / \mathrm{CeO}_{2}$, the feed gas was switched to argon. Then an electric field was applied for $30 \mathrm{~min}$. Subsequently, purge treatment was conducted to extract toluene gas from the chamber atmosphere. The DRIFTS spectra were obtained after each process.

\section{Characterization of catalysts}

The metallic surface area of Pt metal was evaluated using CO pulse measurements (Autosorb iQ; Quantachrome Instruments). For vaporizing adsorbed water on the catalyst, pretreatment was conducted at $673 \mathrm{~K}$ in helium. In addition, STEM images and EDX mapping results were obtained from scanning transmission electron microscopy (STEM; HF-2210; Hitachi Ltd.) to confirm the state of Pt over catalytic supports. The specific surface area of catalysts was examined using nitrogen adsorption with the BET method (Gemini VII; Micromeritics Instrument Corp.). For this experiment, pre-treatment 
was conducted at $473 \mathrm{~K}$ in nitrogen atmosphere for $120 \mathrm{~min}$. Additionally, the electric state of Pt was investigated using XPS measurements (VersaProbe2; ULVAC-PHI, Inc.) without an exposure to air. Orbital $4 \mathrm{f}_{7 / 2}$ and $4 \mathrm{f}_{5 / 2}$ of Pt were measured. For this experiment, $\mathrm{X}$-ray source was $\mathrm{Al} \mathrm{K} \alpha$. The binding energies were referenced to the $\mathrm{C} 1 \mathrm{~s}$ peak at $284.8 \mathrm{eV}$.

\section{Results and discussion}

\section{Promotion effects of electric fields on catalytic activity during MCH dehydrogenation}

After various screening tests, we performed $\mathrm{MCH}$ dehydrogenation over $\mathrm{Pt} / \mathrm{TiO}_{2}$ catalyst as an optimal catalyst at several temperatures from $423 \mathrm{~K}$ to $773 \mathrm{~K}$ with and without an electric field ( $3 \mathrm{~mA}$ of constant current). The resultant catalytic activities are presented in Table 1. Although the applied electric field produced little Joule heat, the increase of the catalyst bed temperature (thermocouple temperature, $T_{\mathrm{tc}}$ ) was no more than $10 \mathrm{~K}$ during the reaction. Additionally, the electric field application drastically improved the catalytic activity. The electric field effect was more remarkable at lower temperatures. Especially at $423 \mathrm{~K}$, the catalytic activity was $17.9 \%$, even in a kinetic condition. That activity exceeded the equilibrium limitation $(5 \%)$ at this temperature.

The values of apparent activation energy were evaluated with and without the electric field to elucidate the promoted catalytic performance of $\mathrm{Pt} / \mathrm{TiO}_{2}$ catalyst by the electric field. Fig. 1 shows Arrhenius plots over $\mathrm{Pt} / \mathrm{TiO}_{2}$ catalyst during $\mathrm{MCH}$ dehydrogenation with (filled plots) and without (blank plots) the electric field. According to these results, the respective values of apparent activation energy were 26.9 and $60.7 \mathrm{~kJ} \mathrm{~mol}^{-1}$ with and without the electric field. Such experimental data indicate that the applied electric field facilitated the $\mathrm{MCH}$ dehydrogenation, and changed the reaction mechanism.

\section{Kinetic analysis and isotope effect during $\mathrm{MCH}$ dehydrogenation in the electric field}

To investigate the role of the applied electric field, partial pressure dependencies were evaluated. Fig. 2 presents results of

Table 1 Catalytic activity during $\mathrm{MCH}$ dehydrogenation with/without the electric field ${ }^{a}$

\begin{tabular}{|c|c|c|c|c|}
\hline \multirow{2}{*}{$\frac{\text { Reaction }}{\text { Temperature/K }}$} & \multicolumn{2}{|c|}{ With EF } & \multicolumn{2}{|c|}{ Without EF } \\
\hline & $T_{\mathrm{tc}} / \mathrm{K}$ & $\mathrm{H}_{2}$ yield/\% & $T_{\mathrm{tc}} / \mathrm{K}$ & $\mathrm{H}_{2}$ yield $/ \%$ \\
\hline 423 & 432 & 17.9 & 423 & 1.2 \\
\hline 473 & 475 & 31.7 & 473 & 10.9 \\
\hline 498 & - & - & 498 & 19.0 \\
\hline 523 & 523 & 58.2 & 523 & 32.6 \\
\hline 573 & 573 & 78.1 & 573 & 63.9 \\
\hline 623 & 623 & 94.4 & 623 & 76.1 \\
\hline 673 & 673 & 99.6 & 673 & 88.3 \\
\hline 723 & 723 & 100.0 & 723 & 94.5 \\
\hline 773 & 773 & 99.9 & 773 & 98.8 \\
\hline
\end{tabular}

${ }^{a} T_{\mathrm{tc}}$ : catalyst-bed temperature measured with a thermocouple.

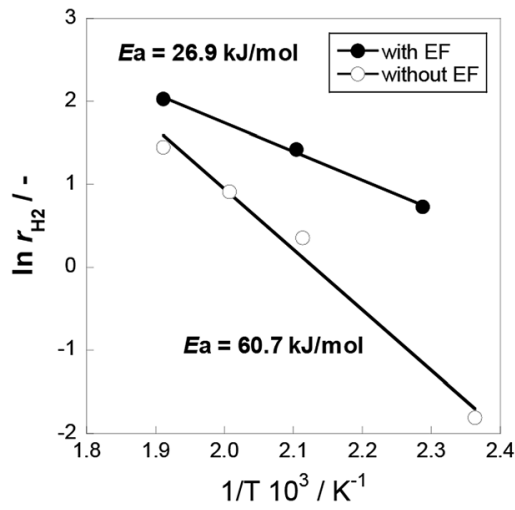

Fig. 1 Arrhenius plots of $\mathrm{Pt} / \mathrm{TiO}_{2}$ with and without the electric field (EF).

partial pressure dependencies of $\mathrm{MCH}$, toluene, and hydrogen. Generally speaking, the catalytic $\mathrm{MCH}$ dehydrogenation is a reversible endothermic reaction. The $\mathrm{MCH}$ dehydrogenation reaction rate is assumed as the following equation using $\mathrm{MCH}$, toluene, and hydrogen partial pressures.

$$
r_{\text {dehydrogenation }}=k[\mathrm{MCH}]^{a}[\text { Toluene }]^{b}\left[\mathrm{H}_{2}\right]^{c}
$$

The dehydrogenation rate was correlated positively with the $\mathrm{MCH}$ partial pressure similarly in both cases: $a$ was 0.49 with the electric field and 0.47 without the electric field. As results over $\mathrm{Pt} / \mathrm{TiO}_{2}$ catalyst, the toluene partial pressure was unrelated to the dehydrogenation rate; $b$ was zero with and without the electric field. This tendency found for the toluene partial pressure, which differs from the well-known Pt catalyst supported on alumina, has been reported for $\mathrm{Pt} / \mathrm{TiO}_{2}$ catalyst. ${ }^{25}$ Accordingly, Pt catalyst supported on $\mathrm{TiO}_{2}$ is more tolerant of inhibition by toluene adsorption during $\mathrm{MCH}$ dehydrogenation. Regarding results of hydrogen partial pressures found with and without the electric field, the $\mathrm{MCH}$ dehydrogenation rate was
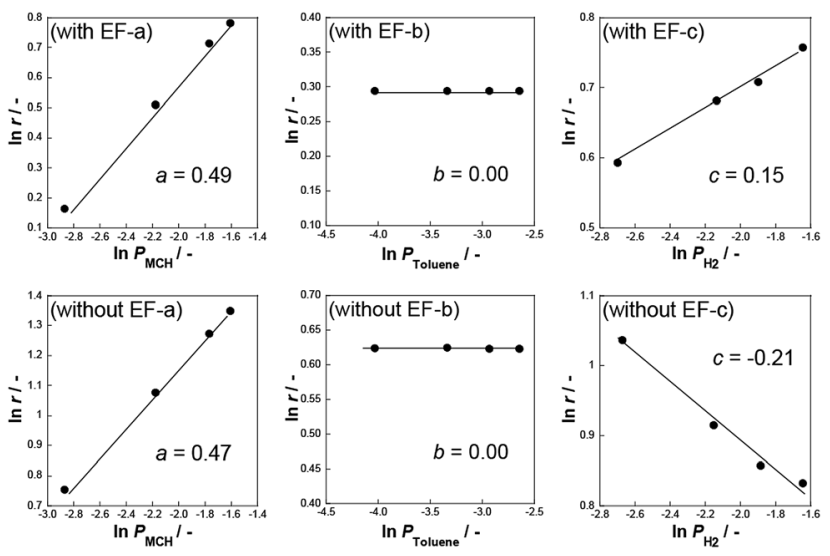

Fig. 2 Partial pressure dependences of (a) methylcyclohexane, (b) toluene, and (c) hydrogen over $\mathrm{Pt} / \mathrm{TiO}_{2}$ for $\mathrm{MCH}$ dehydrogenation. Reaction temperature $423 \mathrm{~K}$ (with EF), $498 \mathrm{~K}$ (without EF), and input current $3 \mathrm{~mA}$. 
Table 2 Isotope effect during $\mathrm{MCH}$ dehydrogenation over $\mathrm{Pt} / \mathrm{TiO}_{2}{ }^{a}$

\begin{tabular}{|c|c|c|c|c|c|}
\hline Condition & & $T_{\mathrm{tc}} / \mathrm{K}$ & $\mathrm{H}_{2}$ production rate $/ \mu \mathrm{mol} \mathrm{min}^{-1}$ & $\mathrm{H}_{2}$ yield/\% & $k_{\mathrm{D}} / k_{\mathrm{H}} /-$ \\
\hline \multirow[t]{3}{*}{ With EF (423 K) } & $\mathrm{MCH}_{\mathrm{H}} / \mathrm{H}_{2}$ & 437 & 109 & 13.8 & - \\
\hline & $\mathrm{MCH}_{\mathrm{H}} / \mathrm{D}_{2}$ & 435 & 134 & 17.1 & 1.24 \\
\hline & $\mathrm{MCH}_{\mathrm{D}} / \mathrm{D}_{2}$ & 433 & 160 & 20.3 & 1.47 \\
\hline \multirow[t]{2}{*}{ Without EF (498 K) } & $\mathrm{MCH}_{\mathrm{H}} / \mathrm{H}_{2}$ & 496 & 169 & 21.5 & - \\
\hline & $\mathrm{MCH}_{\mathrm{H}} / \mathrm{D}_{2}$ & 495 & 182 & 23.2 & 1.08 \\
\hline
\end{tabular}

${ }^{a} T_{\text {tc }}$ : catalyst-bed temperature measured with a thermocouple.

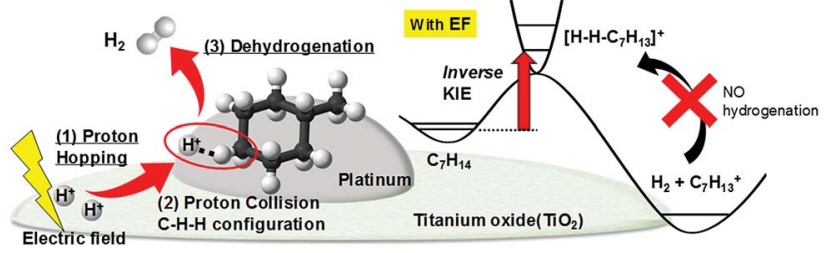

Fig. 3 Mechanism scheme of $\mathrm{MCH}$ dehydrogenation over $\mathrm{Pt} / \mathrm{TiO}_{2}$ in the electric field.
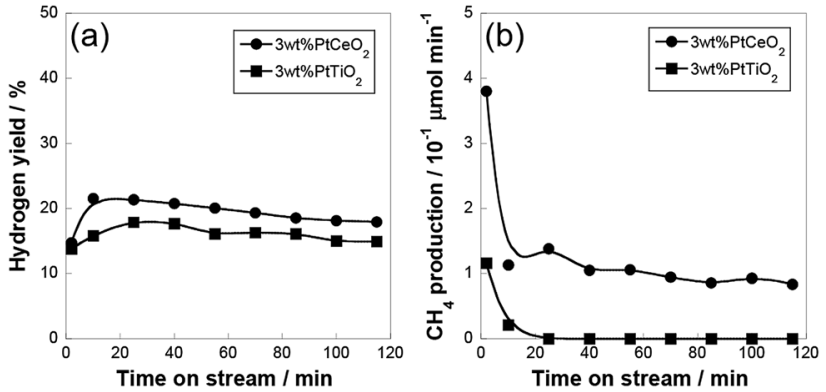

Fig. 4 Results of catalytic activity tests in the electric field over $\mathrm{Pt} / \mathrm{TiO}_{2}$ and $\mathrm{Pt} / \mathrm{CeO}_{2}$ at $423 \mathrm{~K}$ : (a) hydrogen yield and (b) $\mathrm{CH}_{4}$ by-production rate.

negatively correlated by hydrogen without the electric field, $c$ was -0.21 . One can infer that hydrogen promoted reverse toluene hydrogenation without the electric field. However, the
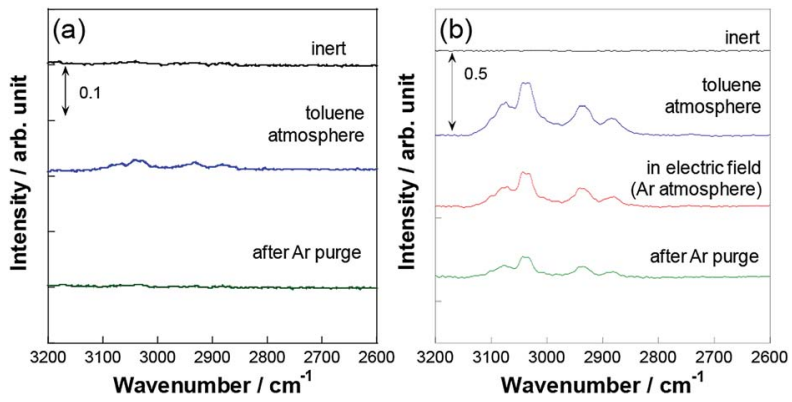

Fig. 5 Spectra of in situ DRIFTS measurements of (a) $\mathrm{Pt} / \mathrm{TiO}_{2}$ and (b) $\mathrm{Pt} / \mathrm{CeO}_{2}$ in various conditions at $423 \mathrm{~K}$. hydrogen partial pressure was positively correlated with the $\mathrm{MCH}$ dehydrogenation rate in the electric field, $c$, was 0.15 , which differs from common results. In earlier studies, such positive values of hydrogen partial pressure dependence are apparent if proton $\left(\mathrm{H}^{+}\right)$hopping occurs on the catalyst surface. ${ }^{26-28}$ In the case of methane steam reforming in the electric field, protons hopped on $\mathrm{Pd} / \mathrm{CeO}_{2}$ catalyst surface and facilitated methane activation by proton collision with methane. ${ }^{24,26}$ Therefore, protons can function as a reaction promoter during $\mathrm{MCH}$ dehydrogenation in the electric field. In the low temperature and low conversion region, toluene and hydrogen, which were products of dehydrogenation had no negative influence on dehydrogenation rate. Therefore, dehydrogenation might proceed with an irreversible process.

To elucidate the role of proton species, isotope effects were confirmed by supplying isotopic $\mathrm{MCH}_{\mathrm{D}}$ and $\mathrm{D}_{2}$ during $\mathrm{MCH}$ dehydrogenation with and without the electric field (Table 2). Here, isotope effects were expressed by the ratio of rate
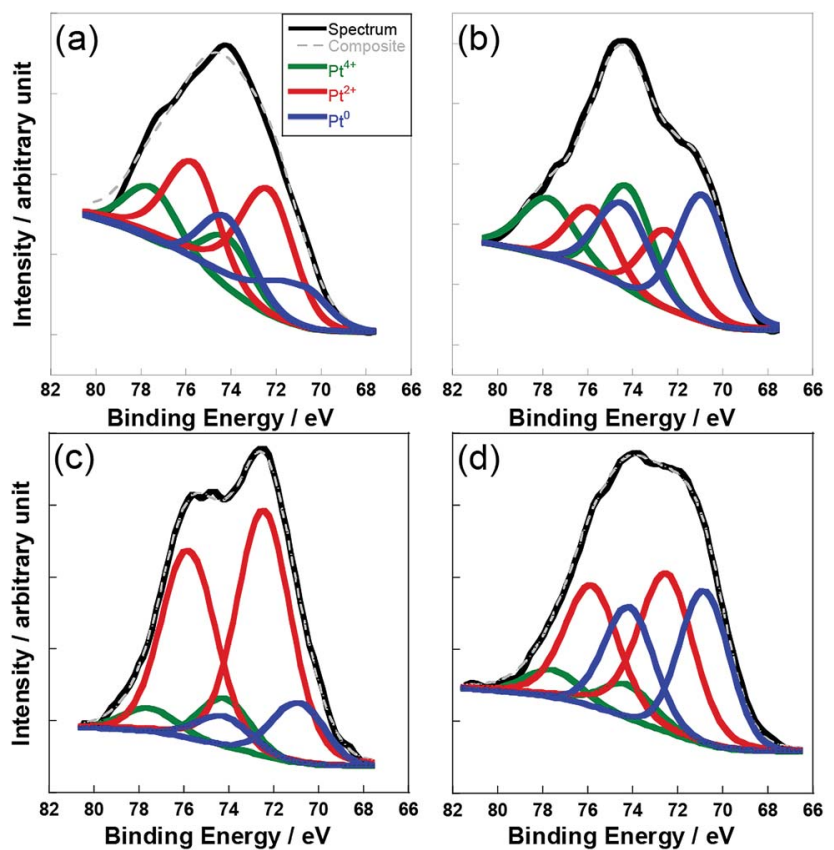

Fig. 6 XPS analysis of the Pt $4 \mathrm{f}_{7 / 2}$ and $4 \mathrm{f}_{5 / 2}$ : (a) $\mathrm{Pt} / \mathrm{TiO}_{2}$ as made, (b) Pt/ $\mathrm{TiO}_{2}$ after $\mathrm{EF}$, (c) $\mathrm{Pt} / \mathrm{CeO}_{2}$ as made, and (d) $\mathrm{Pt} / \mathrm{CeO}_{2}$ after $\mathrm{EF}$. 
Table 3 Electronic state of $\mathrm{Pt}$ on $\mathrm{TiO}_{2}$ and $\mathrm{CeO}_{2}$ from XPS measurement

\begin{tabular}{|c|c|c|c|c|c|c|c|}
\hline & Condition & \multicolumn{3}{|c|}{ Binding energy/eV } & \multicolumn{3}{|c|}{ Relative peak area/\% } \\
\hline $3 \mathrm{wt} \% \mathrm{Pt} / \mathrm{TiO}_{2}$ & After reaction with EF (423 K) & 70.9 & 72.5 & 74.3 & 43.5 & 27.1 & 29.5 \\
\hline $3 \mathrm{wt} \% \mathrm{Pt} / \mathrm{CeO}_{2}$ & As made & 70.9 & 72.4 & 74.2 & 16.5 & 74.8 & 8.8 \\
\hline $3 \mathrm{wt} \% \mathrm{Pt} / \mathrm{CeO}_{2}$ & After reaction with EF (423 K) & 70.8 & 72.5 & 74.3 & 39.8 & 50.0 & 10.3 \\
\hline
\end{tabular}

constants $(k)$ with/without isotope, i.e. $k_{\mathrm{D}} / k_{\mathrm{H}}$ ratio. Generally, $k_{\mathrm{D}} /$ $k_{\mathrm{H}}$ is a value lower than 1 because chemical bonding of heavier isotopes is more stable (lower zero-point energy: ZPE). ${ }^{29}$ Without the electric field, the results follow these general trends when isotope $\mathrm{MCH}_{\mathrm{D}}$ was introduced, $k_{\mathrm{D}} / k_{\mathrm{H}}$ was 0.66 with $\mathrm{MCH}_{\mathrm{D}} / \mathrm{H}_{2}$ and $k_{\mathrm{D}} / k_{\mathrm{H}}$ was 0.69 with $\mathrm{MCH}_{\mathrm{D}} / \mathrm{D}_{2}$. Accordingly, the kinetic isotope effect (KIE) was confirmed without the electric field. Nevertheless, with the electric field, $k_{\mathrm{D}} / k_{\mathrm{H}}$ increased as a larger proportion of deuterium was introduced into the reactor, as shown in Table 2. This inverse KIE has been observed when $\mathrm{C}-\mathrm{H}-\mathrm{H}$ configuration was formed through proton collision, ${ }^{24}$ explained by the ZPE discrepancy on isotopes. ${ }^{24,30-34}$ During MCH dehydrogenation in the electric field, inverse KIE are observed by the collision of accelerated proton with $\mathrm{H}$ (or D)atoms of $\mathrm{MCH}$ to form $\left[\mathrm{H} \text { (or D) }-\mathrm{H} \text { (or D) }-\mathrm{C}_{7} \mathrm{H}_{13}\right]^{+}$over $\mathrm{Pt} / \mathrm{TiO}_{2}$ catalyst, to advance the reaction of $\mathrm{MCH}$ dehydrogenation further. After dehydrogenation, the resultant state of $\mathrm{C}_{7} \mathrm{H}_{13}{ }^{+}+$ $\mathrm{H}_{2}$ has much lower energy level than the three-atom transition and the initial physisorption state (Fig. 3). In this case, reverse hydrogenation has larger activation energy, making it difficult to proceed..$^{24,31,32,34}$ Thereby, results suggest that the applied electric field promoted proton hopping and $\mathrm{MCH}$ dehydrogenation to show higher catalytic activity beyond the equilibrium limitation (Fig. 3).

\section{Methane by-production suppression and the electric state of platinum on $\mathrm{Pt} / \mathrm{TiO}_{2}$ catalyst}

Methane by-production rate and coke deposition over $\mathrm{Pt} / \mathrm{TiO}_{2}$ catalyst were investigated during $\mathrm{MCH}$ dehydrogenation at 423 $\mathrm{K}$ in the electric field. Only slight to no coke deposition occurred in this catalyst system (ESI Table S1 $\dagger$ ). Also, the structure of catalyst was not changed even after the reaction in the electric field (ESI Table S2 $\uparrow$ ). Fig. 4 presents results of the catalytic activity and methane by-production rate during $120 \mathrm{~min}$ of dehydrogenation. For better comparison, results over $\mathrm{Pt} / \mathrm{CeO}_{2}$ catalyst are also presented in Fig. 4. Results show that $\mathrm{Pt} / \mathrm{TiO}_{2}$ had no methane by-production after 10-25 min of dehydrogenation as the applied electric field being stabilized. According to the partial pressure dependency of toluene, $\mathrm{Pt} / \mathrm{TiO}_{2}$ catalyst showed high tolerance against inhibition by toluene adsorption during MCH dehydrogenation both with and without the electric field. Methane by-production reportedly occurs with hydrodemethylation of produced toluene during $\mathrm{MCH}$ dehydrogenation. Consequently, the toluene behavior over $\mathrm{Pt} / \mathrm{TiO}_{2}$ is regarded as related to the methane by-production rate during dehydrogenation.
DRIFTS measurements were conducted over $\mathrm{Pt} / \mathrm{TiO}_{2}$ and $\mathrm{Pt} /$ $\mathrm{CeO}_{2}$ catalysts supplying toluene on the catalyst surface, as shown in Fig. 5. In the case of $\mathrm{Pt} / \mathrm{TiO}_{2}$, the electric field cannot be stable and applicable in the DRIFTS system because of the cell structure. Therefore, in situ DRIFTS with the electric field was conducted over $\mathrm{Pt} / \mathrm{CeO}_{2}$ instead of $\mathrm{Pt} / \mathrm{TiO}_{2}$. Regarding the $\mathrm{Pt} / \mathrm{CeO}_{2}$ catalyst, toluene adsorption was observed both with and without the electric field $(\mathrm{C}-\mathrm{H}$ stretching around $\left.3000 \mathrm{~cm}^{-1}\right) .^{35,36}$ However, the IR peaks for toluene are barely visible over $\mathrm{Pt} / \mathrm{TiO}_{2}$ catalyst, even under a toluene atmosphere. Furthermore, the peaks disappeared completely after purge treatment. These results demonstrate that $\mathrm{Pt} / \mathrm{TiO}_{2}$ catalyst can suppress toluene adsorption and methane by-production during $\mathrm{MCH}$ dehydrogenation.

Fig. 6 and Table 3 present results of XPS measurements for Pt over $\mathrm{Pt} / \mathrm{TiO}_{2}$ and $\mathrm{Pt} / \mathrm{CeO}_{2}$. The XPS peaks for $4 \mathrm{f}_{7 / 2}$ and $4 \mathrm{f}_{5 / 2}$ orbitals are divisible into three states: $\mathrm{Pt}^{0}, \mathrm{Pt}^{2+}$, and $\mathrm{Pt}^{4+} \cdot{ }^{37}$ Here, $\mathrm{Pt}^{4+}$ was assumed as embedded $\mathrm{Pt}$ with strong metal and support interaction (SMSI). As SMSI is known to occur readily between $\mathrm{Pt}$ and $\mathrm{TiO}_{2}$ (ref. 25) because Pt is highly dispersed and not aggregated (shown in ESI Fig. S2 $\dagger$ ), it might be the reason why $\mathrm{Pt} / \mathrm{TiO}_{2}$ showed lower surface area than $\mathrm{Pt} / \mathrm{CeO}_{2}$ did (ESI Table S2 $\dagger$ ). Larger amounts of Pt might be embedded inside the $\mathrm{TiO}_{2}$ support. Pt reducibility was estimated and compared over $\mathrm{Pt} / \mathrm{TiO}_{2}$ and $\mathrm{Pt} / \mathrm{CeO}_{2}$ from the ratio of $\left(\mathrm{Pt}^{0}+\mathrm{Pt}^{2+}\right) / \mathrm{Pt}^{4+}$. $\mathrm{Pt}$ on $\mathrm{TiO}_{2}$ showed more peak area for $\mathrm{Pt}^{4+}$ even after the reaction in the electric field, so the reducibility of $\mathrm{Pt}^{4+}$ in/on $\mathrm{TiO}_{2}$ seems low due to the SMSI. On the other hand, comparing $\mathrm{Pt}^{2+}$ and $\mathrm{Pt}^{0}, \mathrm{Pt}$ on $\mathrm{Pt} / \mathrm{TiO}_{2}$ is more metallic after the reaction in the electric field. It has been described in earlier reports that supported Pt is more easily reduced in the electric field, ${ }^{38}$ and $\mathrm{TiO}_{2}$ can donate electrons to $\mathrm{Pt}^{25}$ The interaction between Pt and $\pi$ coordination of toluene can be weakened over reductive $\mathrm{Pt}^{25}$ Consequently, reductive Pt over $\mathrm{Pt} / \mathrm{TiO}_{2}$ catalyst is important for high tolerance against toluene inhibition and methane byproduction.

\section{Conclusions}

Dehydrogenation of methylcyclohexane ( $\mathrm{MCH})$ was conducted over $\mathrm{Pt} / \mathrm{TiO}_{2}$ catalyst by applying an electric field. The electric field promoted the reaction to achieve $17.9 \%$ hydrogen yield, even at $423 \mathrm{~K}$ and a kinetic condition, under which the catalytic activity exceeded the equilibrium limitation (5\%). Despite the reversibility of dehydrogenation, the reaction rate was positively correlated with the partial pressure of hydrogen with the electric 
field application. Additionally, an inverse kinetic isotope effect (KIE) was observed with isotope $\mathrm{MCH}_{\mathrm{D}}\left(\mathrm{C}_{7} \mathrm{D}_{14}\right)$ and $\mathrm{D}_{2}$ in the electric field. These results indicate that hydrogen-derived species, i.e. protons, promoted the abstraction of $\mathrm{H}$-atoms from $\mathrm{MCH}$ for dehydrogenation. Furthermore, $\mathrm{Pt} / \mathrm{TiO}_{2}$ catalyst, different from other catalysts, showed neither methane nor coke by-production during $\mathrm{MCH}$ dehydrogenation in the electric field at $423 \mathrm{~K}$. DRIFTS measurements revealed that toluene was only slightly adsorbed over $\mathrm{Pt} / \mathrm{TiO}_{2}$ catalyst. XPS measurements demonstrated that $\mathrm{Pt}$ on $\mathrm{TiO}_{2}$ was more metallic after applying the electric field. Actually, $\mathrm{TiO}_{2}$ is known to be capable of donating electrons to the empty orbital of Pt. Therefore, we inferred that more metallic $\mathrm{Pt}$ on $\mathrm{TiO}_{2}$ support weakened interaction between $\mathrm{Pt}$ and $\pi$-coordination of toluene. In conclusion, results show that $\mathrm{Pt} / \mathrm{TiO}_{2}$ catalyst promotes $\mathrm{MCH}$ dehydrogenation selectively at low temperatures by virtue of proton hopping in the electric field.

\section{Conflicts of interest}

There are no conflicts to declare.

\section{Acknowledgements}

This study was supported by JST-CREST JPMJCR1423 and JSPS Grants-in-Aid for Scientific Research - KAKENHI.

\section{References}

1 M. Balat, Int. J. Hydrogen Energy, 2008, 33, 4013-4029.

2 T. Sinigaglia, F. Lewiski, M. Eduardo, S. Martins and J. C. M. Siluk, Int. J. Hydrogen Energy, 2017, 42, 24597-24611.

3 S. Sharma and S. K. Ghoshal, Renewable Sustainable Energy Rev., 2015, 43, 1151-1158.

4 A. Klerke, C. H. Christensen, J. K. Norskov and T. Vegge, J. Mater. Chem., 2008, 18, 2304-2310.

5 R. Lan, J. T. S. Irvine and S. Tao, Int. J. Hydrogen Energy, 2012, 37, 1482-1494.

6 F. Alhumaidan, D. Cresswell and A. Garforth, Energy Fuels, 2011, 25, 4217-4234.

7 E. Gianotti, M. Taillades-Jacquin, J. Roziere and D. J. Jones, ACS Catal., 2018, 8, 4660-4680.

8 Y. Okada, E. Sasaki, E. Watanabe, S. Hyodo and H. Nishijima, Int. J. Hydrogen Energy, 2006, 31, 1348-1356.

9 R. B. Biniwale, S. Rayalu, S. Devotta and M. Ichikawa, Int. J. Hydrogen Energy, 2008, 33, 360-365.

10 A. Shukla, J. Pande and R. B. Biniwale, Int. J. Hydrogen Energy, 2012, 37, 3350-3357.

11 N. Boufaden, R. Akkari, B. Pawelec, J. L. G. Fierro, M. S. Zina and A. Ghorbel, J. Mol. Catal. A: Chem., 2016, 420, 96-106.

12 L. W. Jossens and E. E. Petersen, J. Catal., 1982, 73, 377-386.

13 B. Liu, Z. Wang, Q. Zhu, X. Li and J. Wang, Fuel, 2017, 200, 387-394.
14 G. Maria, A. Marin, C. Wyss, S. Muller and E. Newson, Chem. Eng. Sci., 1996, 51, 2891-2896.

15 W. Wang, L. Miao, K. Wu, G. Chen, Y. Huang and Y. Yang, Int. J. Hydrogen Energy, 2019, 44, 2918-2925.

16 D. K. Cromwell, P. T. Vasudevan, B. Pawelec and J. L. G. Fierro, Catal. Today, 2016, 259, 119-129.

17 N. Boufaden, R. Akkari, B. Pawelec, J. L. G. Fierro, M. Said Zina and A. Ghorbel, Appl. Catal., A, 2015, 502, 329-339.

18 N. Boufaden, B. Pawelec, J. L. G. Fierro, R. Guil López, R. Akkari and M. Said Zina, Mater. Chem. Phys., 2018, 209, 188-199.

19 A. Nakano, S. Manabe, T. Higo, H. Seki, S. Nagatake, T. Yabe, S. Ogo, T. Nagatsuka, Y. Sugiura, H. Iki and Y. Sekine, Appl. Catal., A, 2017, 543, 75-81.

20 Y. Sugiura, T. Nagatsuka, K. Kubo, Y. Hirano, A. Nakamura, K. Miyazawa, Y. Iizuka, S. Furuta, H. Iki, T. Higo and Y. Sekine, Chem. Lett., 2017, 46(11), 1601-1604.

21 S. Manabe, T. Yabe, A. Nakano, S. Nagatake, T. Higo, S. Ogo, H. Nakai and Y. Sekine, Chem. Phys. Lett., 2018, 711, 73-76. 22 F. Alhumaidan, D. Tsakiris, D. Cresswell and A. Garforth, Int. J. Hydrogen Energy, 2013, 32, 14010-14026.

23 W. F. Greenlee, J. D. Sun and J. S. Bus, Toxicol. Appl. Pharmacol., 1981, 59, 187-195.

24 S. Okada, R. Manabe, R. Inagaki, S. Ogo and Y. Sekine, Catal. Today, 2018, 307, 272-276.

25 S. Nagatake, T. Higo, S. Ogo, Y. Sugiura, R. Watanabe, C. Fukuhara and Y. Sekine, Catal. Lett., 2016, 146, 54-60.

26 R. Manabe, S. Okada, R. Inagaki, K. Oshima, S. Ogo and Y. Sekine, Sci. Rep., 2016, 6, 38007.

27 K. Oshima, T. Shinagawa, Y. Nogami, R. Manabe, S. Ogo and Y. Sekine, Catal. Today, 2014, 232, 27-32.

28 R. Inagaki, R. Manabe, Y. Hisai, Y. Kamite, T. Yabe, S. Ogo and Y. Sekine, Int. J. Hydrogen Energy, 2018, 43, 14310-14318.

29 G. A. Olah and R. H. Schlosberg, J. Am. Chem. Soc., 1968, 90, 2726-2727.

30 G. A. Olah, G. Klopman and R. H. Schlosberg, J. Am. Chem. Soc., 1969, 91, 3261-3268.

31 G. C. Schatz and A. F. Wagner, J. Phys. Chem., 2018, 88, 221232.

32 B. Kerkeni and D. C. Clary, J. Phys. Chem. A, 2004, 108, 89668972.

33 K. B. Wiberg, Chem. Rev., 1955, 55, 713-743.

34 M. J. Kurylo, G. A. Hollinden and R. B. Timmons, J. Chem. Phys., 1970, 52, 1773-1781.

35 M. D. Hernandez, I. Tejedor-Tejedor, J. M. Coronado and M. A. Andreson, Appl. Catal., B, 2011, 101, 283-293.

36 D. Murzin, T. Salmi, S. Smeds, M. Laatikainen, M. Mustonen and E. Paatero, React. Kinet. Catal. Lett., 1997, 61, 227-236.

37 P. Bera, K. R. Priolkar, A. Gayen, P. R. Sarode, M. S. Hegde, S. Emura, R. Kumashiro, V. Jayaram and G. N. Subbanna, Chem. Mater., 2003, 15, 2049-2060.

38 S. Sakurai, S. Ogo and Y. Sekine, J. Jpn. Pet. Inst., 2016, 59(5), 174-183. 